\title{
Playing according to the game plan
}

\section{Cambridge}

"WE are the envy of most Antarctic nations", asserts Barry Heywood, deputy director of the British Antarctic Survey (BAS). Heywood's brash self-confidence, a rarity among contemporary British scientists, stems from two linked developments that transformed the fortunes of BAS during the 1980 s. First, BAS's annual budget grew in real terms by more than 60 per cent between $1982-83$ and 1990-91, when it reached $£ 16.3$ million. Second, the British scientific presence in the Antarctic has become perhaps the best coordinated of any of the Antarctic nations, centred around a clear long-term strategy.

The turning-point for BAS, after a decade of neglect in the 1970 s, came with the Falklands conflict of 1982. Investment in the South Atlantic and Antarctic suddenly became a political priority, once British forces had regained the islands from Argentina. In 1983, the government approved plans put forward by Sir Hermann Bondi, then chairman of the Natural Environment Research Council (NERC), to expand British Antarctic research. Bondi's original plans, refined and extended, form the backbone of a glossy NERC document of 1989, Antarctica 2000, which defines the direction of British Antarctic science over the next decade.

To match BAS's activities to the developing NERC strategy, BAS was restructured in 1987 into six new science divisions: Ice and Climate, Geology, Geophysics, Terrestrial and Freshwater Life Sciences, Marine Life Sciences, and Upper Atmospheric Sciences. The new structure (which replaced the traditional academic division into atmospheric, Earth and life sciences) brings together researchers, often from different disciplines, to focus on the themes laid down in the NERC strategy.

This approach is best evident in the ice and climate division, which has united glaciologists and atmospheric scientists to provide data vital to modellers attempting to predict the pattern of climate change. For example, BAS scientists are now measuring the transport of water vapour into the atmosphere over the Antarctic, and its deposition as snow on the continent. The data will be used to refine the UK Meteorological Office's global climate model.

The centralization of British Antarctic research around the NERC strategy and BAS was completed with the opening of a new and larger headquarters building at BAS's Cambridge site in 1989. Staff have now been moved into the building from BAS's former outposts all over the country. The end result is a coherent research effort, Heywood says, which benefits from having the logistics of conducting research in the Antarctic and the direction of the science itself controlled by the same people.

Most BAS staff agree with Heywood, although some grumble about the unavoid- able bureaucracy associated with a large institute format. NERC reviews the progress of BAS science annually, and BAS's management every five years or so. In addition, BAS must report twice a year directly to the Department of Education and Science. Producing these reports may divert BAS staff occasionally from their scientific objectives, but is a small price to pay for the protected level of core funding that BAS currently enjoys.

The centralized British approach contrasts strongly with that of most Antarctic nations. In the United States, which supports more Antarctic research than any other nation, there is no directed Antarctic research programme - the dispersed US Antarctic science community relies for its funding on the usual National Science Foundation grant process. Heywood feels that the result is

\section{RESEARCH COMPUTING}

\section{Logging-on on the ice}

ThreE years ago, Grahame Hughes, BAS's computing chief, set himself an ambitious goal: to supply researchers at the British bases in Antarctica with computing facilities as good as those enjoyed by their colleagues in Cambridge.

That aim is close to being realized. The Halley base now has a VAX digital computer with a network of terminals, giving scientists there a smaller version of the network at BAS headquarters. The two networks communicate directly on a daily basis, via the Inmarsat communications satellite. Researchers at Halley can send large data files back to Cambridge to be processed there (or even on supercomputers, via the JANET network), and receive sometimes a "mixed bag" of research projects.

Given the huge costs and logistic difficulty of transporting people and equipment to Antarctica, Heywood says that BAS's centralized programme represents the most cost effective way of spending the smaller UK budget. "Antarctica isn't a place where you can catch the number 39 bus, do your bit of research, and come home", he says.

But Heywood is aware that some British scientists are hostile to large directed research programmes, arguing that they bleed money from research grant support. Heywood points out that BAS is providing over $£ 1$ million over the three years to the end of 1992 , to set up and provide logistic support for university research projects in Antarctica. RESEARCHCOLLABORATION

\section{Magnetic poles together}

THE British Halley base hosts the Antarctic component of a unique collaboration to study the interactions between the solar wind and the Earth's upper atmosphere, and between the Sun's and the Earth's magnetic fields. Using large radar arrays, British and US physicists are viewing the Antarctic and Arctic skies simultaneously like two "huge television screens", says John Dudeney, head of BAS's Upper Atmospheric Sciences division.

The solar wind is a stream of charged particles, channelled out into the Solar System along the Sun's magnetic field lines. Some of these field lines fuse with those of the Earth, which come to ground at the poles. Charged particles then rain down into the polar atmosphere, causing spectacular aurorae.

PACE (the Polar Anglo-American Conjugate Experiment) relies on two arrays of high-frequency radar antennas. The 250metre-long Halley array has been built to the results in a matter of days. Before, Halley had only a handful of personal computers, and communicated with Cambridge via facsimile machine.

The new electronic link also means that Hughes and his colleagues can iron out problems that arise in the Halley network from Cambridge, logging on to the Halley machine while data files are transferred.

BAS's new research ship, the James Clark Ross, will carry a similar computing network, and Hughes hopes to extend the facility to other British Antarctic bases in the near future. Late last year, he obtained five small secondhand VAX machines at a knock-down price, which are now waiting to be shipped to Antarctica. complement a similar structure at Goose Bay in Labrador, Canada, run by a team from Johns Hopkins University in Baltimore, Maryland. The radars each scan several million square kilometres of the polar sky for 'ripples' in the ionosphere.

Dudeney hopes that data from PACE, together with satellite observations, will allow physicists to develop a sound quantitive model to predict the behaviour of the ionosphere from observations of the Sun's surface. At the peak of the 11-year solar cycle, as the sunspot number reaches a maximum, strong gusts in the solar wind can cause magnetic storms in the far north and south. In 1989, a particularly severe storm fused a large proportion of Quebec's electric power lines. The disruption could have been minimized had there been some advance warning. With the next solar maximum due at the turn of the century, Dudeney and his colleagues are working to a deadline. 